\title{
Measuring Instruments Control Methodology Performance for Analog Electronics Remote Labs
}

\author{
http://dx.doi.org/10.3991/ijoe.v8iS4.2191 \\ U. Hernández-Jayo, J. García-Zubía \\ University of Deusto, Bilbao, Spain
}

\begin{abstract}
- this paper presents the work that has been developed in parallel to the VISIR project. The objective of this paper is to present the results of the validations processes that have been carried out to check the control methodology. This method has been developed with the aim of being independent of the instruments of the labs.
\end{abstract}

Index terms - control method; remote lab; VISIR platform extension

\section{INTRODUCTION}

Practical exercises and experiments are fundamental in any technical discipline either in educational or investigation areas. To achieve that, the easier way to implement these activities is to go to hands-on laboratories, which offer real equipments and experiments. However, sometimes many of these experiments require special and expensive instruments or the number of needed equipments is not enough for all the potential users due to their size or maintenance requirements.

At a scenario like this, virtual laboratories or remote laboratories can play a key role in the teaching of specific areas of technical subjects such as analog electronics. While virtual laboratories can be used in certain experimental activities in which the simulation may be enough, they are not as effective as the laboratories in which users can play and interact with real equipment [1], according to the learning-by-touching or active learning approaches. Moreover, according to the Accreditation Board for Engineering and Technology (ABET), practical exercises should help the students to achieve a set of competences that virtual labs cannot satisfy [2].

Therefore, the manual remote laboratories (or simply remote laboratories) try to reproduce remotely and as faithfully as possible the actions that the user carries out at local laboratories. Thus the advantages that these technology platforms of learning can provide respect for others are:

- Ubiquitous access to experiments through an Internet-based communication.

- They can play a complementary role to the theoretical sessions and classroom practices, so the student can return again and again on the learned concepts and practice by their selves.

- Remote labs help to improve the performance of the available equipments, increasing the accessing time $24 \mathrm{~d} / 7 \mathrm{~h}$.

Starting with these premises and on the basis of our experience in distance learning using WebLabs [3], on the particular topic of analog electronics remote labs, technical contributions can be made in the following aspects:

- Enable users to build electronic circuits such as if they were in a hands-on laboratory.

- Obtain consistency and reliability in the measurements are taken in a remote way.

- Make easy the maintenance and scalability of the laboratory regarding the instruments and experiments.

This paper describes a model for the design of a control, measurement and configuration system of electronic circuits to be deployed in remote learning platforms. Users can build real circuits and carry out measurements on them with typical instruments of an electronic workbench: oscilloscope, function generator, power supply and digital multimeter.

From the analysis of the role that remote experimentation can play in the practice of electronics, we introduce the application area of development of the proposed model, describing its main technical aspects concerning its implementation.

According to the described model, a prototype has been developed and deployed in a remote laboratory. In this way, the effectiveness and reliability tests can be carried out to check the validity of the model as a tool for remote prototyping and interactions

\section{SCOPE OF THE PRESENTED WORK}

Based on the previous analysis of the most important remote labs, NetLab [4], RemotElectLab [5] ISILab [6] and iLab [7], focus on analog electronics, and thanks to our experience in the VISIR consortium [7], we propose in this work a new control methodology whose main objectives are:

- Get a software control solution that can be used with commercial instruments commonly found in an electronic lab, but at the same time this solution must be independent of the manufacturer of the equipments.

- The control method must provide tools and solutions to allow users to build and carry out measures over the electronic circuits in a remote way. The user must be able to execute almost the same actions as he were in a traditional or manual lab.

- The maintenance of the remote lab that deploys this control solution must be simple to allow add, remove or replace components, circuits and instruments in an easy way without any recodification of the control software. 
With this method we provide some developments to be deployed in specific systems of the architecture of a remote lab, leaving out of this work the development of the web client and other functions related to the server of a remote lab (Figure 1). The physical architecture of the proposed solution is shown in Figure 2, where the systems in which we have worked are the following ones [8]:

1. Software control application: it is based on the VISIR logic architecture (using two server entities). This control application is the set of algorithms used to control the experiments, based on the commands and actions performed by the user in the web client. The goal of this application is that it can be used to control any instruments regardless of the manufacturer and the control interface. To achieve this, we have developed a set of algorithms in LabVIEW in which IVI drivers have been used to access to the control functions of the instruments. The only one restriction is that the used equipments must be compliant with IVI standard, but nowadays, most of the main manufactures provided this kind of drivers.

2. Control interface: it is in charge of the communication between the software control application and the experiments (instruments + circuits under test). The goal is to select a technology that could be easy deployable with a good quality of service without need a specific hardware. We have chose LXI as control interface because as it is based on Ethernet, it is easily deployable and simple networks equipments, as a hub, are required to build the instruments network in the lab. LXI is our chosen technology, but thanks to the independence of the software application respect to the interface control, any other control interface can be used in combination with the control algorithms. That is, the control application is independent of the control interface.

3. Experiments control system: this system is responsible of enable remote construction of the circuit under test, feed it and excite with the signals configured by the user with the tools and instruments provided in web client. To test it, we have used a commercial switching matrix (Agilent 34980A and 34932) and we have designed simple expansion modules. The target of these modules is to connect components (resistors, capacitors, diodes, etc) and instruments into the matrix and perform the interconnection between them. As the others instruments of the lab, this switching matrix can be replace by other model and manufacturer without changing any code of the control algorithms.

In addition, the proposed method aims to improve some features of the experiments control system used in the VISIR system, increasing the performance of the switching matrix with respect to the one used in the VISIR, reducing the number of components required in experiments and without needing to add special components to enable the current measurements in the circuit under test.

\section{PROTOTYPE}

A prototype for the proposed model has been developed with main objectives of validating its effectiveness as control and measurement system and setting up a framework to evaluate its performance in a real analog electronic remote lab.

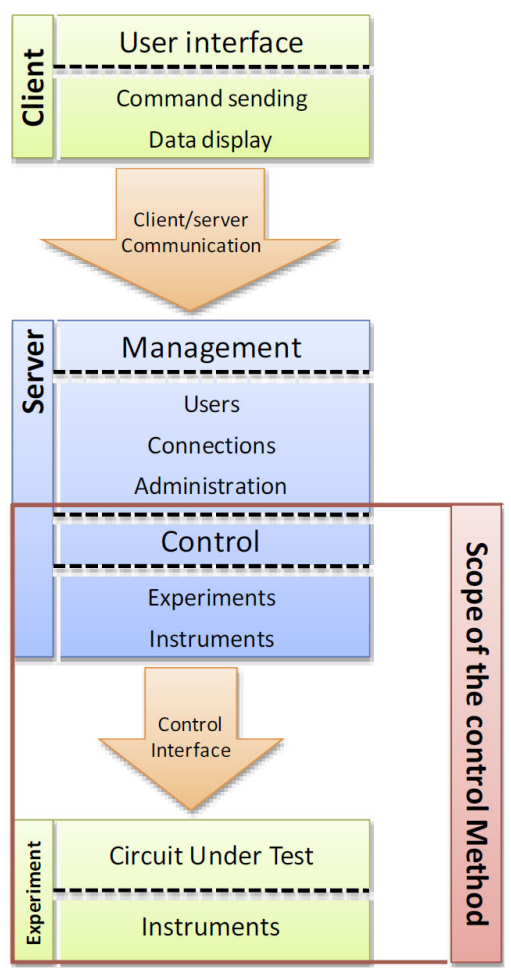

Figure 1. Scope of the proposed method respect to remote lab architecture

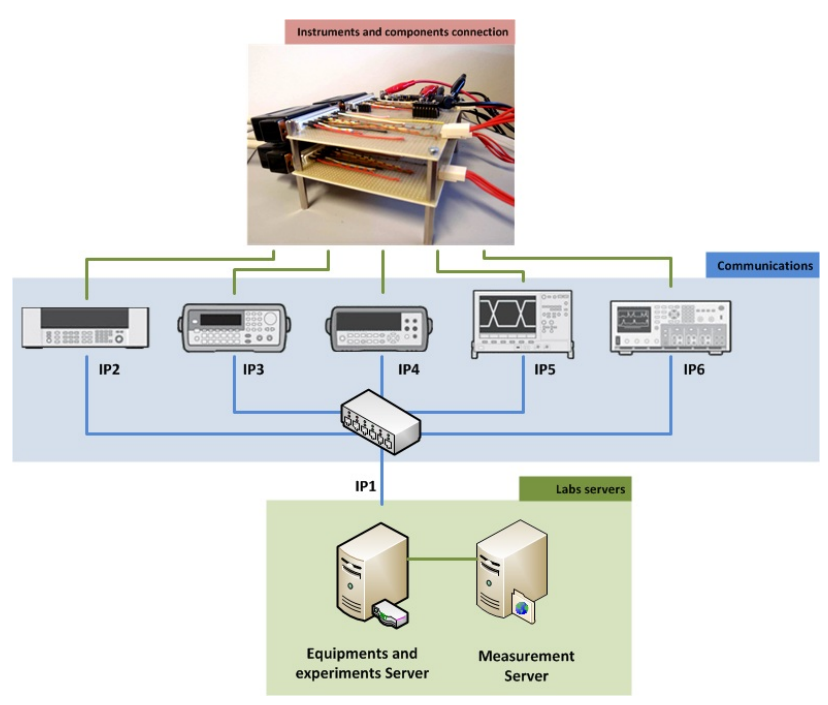

Figure 2. Architecture of the control system

This prototype allows the users to interact with electronics components and carry out measurements using a set of real instruments: oscilloscope, function generator, multimeter and power supply. As the scope of the proposed approach does not include a web client, in this prototype the one developed at the VISIR project has been deployed [8]. This web interface offers a set of front panels of all available instruments in the lab as well as a virtual breadboard in which the users build the CUT that later will be implemented physically using the switching matrix.

The others systems that are required to obtain a complete and functional remote lab are provided by the WebLab-Deusto. 
With this software and communications architecture, we have provided the prototype with the following instruments:

- 33220A Function generator

- 34410A Digital multimeter

- DSO5012A Oscilloscope

- N5746A Power supply

- 34980A Mainframe with two 34932A switching matrix modules.

Once the instruments are deployed, these are connected by the LXI interface to a hub that also connects the computer in which the Control Server applications run.

\section{VALIDATION OF THE PROPOSED METHOD}

To validate the proposed method, we have carried out the following tests using a remote lab in which we have deployed this control method: we have used the architecture provided by the WebLab-Deusto and the web client developed in the VISIR project Figure 3).

- We have verified that the system allows building and measuring electronic circuits in a remote way without introducing significant errors in the measures. These measures have been performed by real users using the lab at the same time and implementing different circuits and measures.

- We have measured the time response of the control system and then we have compared it with the system developed in the laboratory VISIR. Still presenting a further delay in the response, it does not reach 10 seconds, value that it is considered as maximum for a web site response.

- We have characterized the proposed experiment control system, that is, we have measured the value of the error resistance introduced in the circuit under test by the matrix and the expansion modules. The results determine that the error in the measure because of this resistance is minimal.

- We have compared the measures read on a same circuit but carried out them in different scenarios and using always the same electronic components: using the lab that deploys the proposed method, using the VISIR remote lab and using a hands-on or traditional laboratory. The results are conclusive: barely there are differences between the measurements taken in these scenarios.

- We have compared the number of components need to make certain circuits and measures using our system and the VISIR. We have observed that the performance of our experiments control system is better than the VISIR because to build the same circuits, we need less number of components and we don't need to add shortcuts to the matrix to allow certain measures and connections.

The objectives of the validation phase are:

- to check that the remote measurement and control system does not introduce errors respect the results obtained in a hands-on lab.

- to verify that the system time response is suitable even when the measures are carried out in concurrent mode.

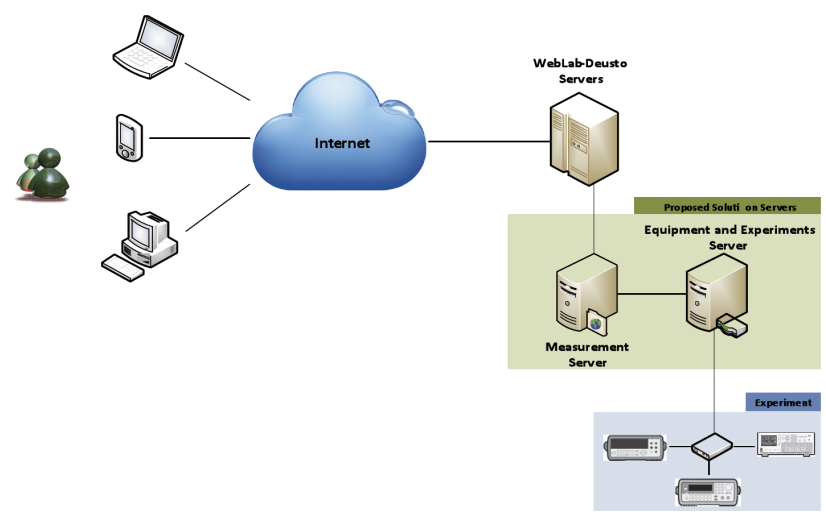

Figure 3. Scenario for the validation

\section{A. Measurements validation}

In this test we want to validate that if a CUT is created remotely using the same components as in a hands-on lab, the measurements carried out using the proposed model are the same. To perform this probe, first we have made the measures in the local labs using a breadboard and some discrete components. After that, we have removed the components from the breadboard and placed them in the designed switching matrix. The measures also have been carried out with the same instruments in both scenarios. These are the test bench experiments:

- Periodic signal characterization: the oscilloscope has been connected directly to the function generator.

- Serial resistors configuration: some resistances area connected in serial. The equivalent circuit is measured using the digital multimeter.

- Parallel resistors configuration: some resistances area connected in parallel. The equivalent circuit is measured using the digital multimeter

- Voltage measures: using a voltage divider configuration.

- Current measures: in a 3 resistors network.

- Frequency circuits characterization: using a half wave-rectifier with a filter at the output and a function generator and the oscilloscope.

These experiments have been performed by ten users, some of them without skills in electronics. In the same way, some of them have never used a remote lab before. In this scenario, each user had to practice with 6 different experiments. The order of the experiments was random, so the control and measurement system had to set up different CUT and instruments in concurrent mode. The obtained measures are shown at Table I.

Analyzing these results, it can be said that:

- In the periodic signal measures, the remote system offers almost the same frequency values. In the amplitude measures, there is a little deviation.

- In the measurement of resistors configuration, the remote system provides valid results, taking into account that the tolerance of the resistances are the same.

- In the measurement of voltage and current, the remote system is a stable, providing results that are almost the same in both remote and manual scenarios. 
TABLE I.

REMOTE AND MANUAL MEASUREMENTS IN REAL EXPERIMENTS

\begin{tabular}{|c|c|c|c|}
\hline Experiment & $\begin{array}{c}\text { Manual } \\
\text { Measures }\end{array}$ & $\begin{array}{c}\text { Remote } \\
\text { Measures }\end{array}$ & $\begin{array}{c}\text { Error } \\
\%\end{array}$ \\
\hline $\begin{array}{c}\text { Periodic Signals } \\
\mathrm{F}_{\mathrm{T}}=1 \mathrm{Khz} ; \mathrm{V}_{\mathrm{T}}=20 \mathrm{~V}\end{array}$ & $999 \mathrm{~Hz}$ & $999.4 \mathrm{~Hz}$ & 0.04 \\
\cline { 2 - 4 } & $20.1 \mathrm{~V}$ & $19.99 \mathrm{~V}$ & 0.54 \\
\hline $\begin{array}{c}\text { Resistances } \\
\text { Serial Conf. } \\
\mathrm{R}_{\mathrm{T}}=1470 \Omega\end{array}$ & $1456 \Omega$ & $1462.4 \Omega$ & 0.43 \\
\hline $\begin{array}{c}\text { Resistances } \\
\text { Parallel Conf. } \\
\mathrm{R}_{\mathrm{T}}=448 \Omega\end{array}$ & $445.6 \Omega$ & $447.2 \Omega$ & 0.35 \\
\hline $\begin{array}{c}\text { Voltage Divider } \\
\mathrm{V}_{\mathrm{T}}=12.59 \mathrm{~V}\end{array}$ & $12.59 \mathrm{~V}$ & $12.59 \mathrm{~V}$ & 0 \\
\hline $\begin{array}{c}\text { Current Measures } \\
\mathrm{I}_{\mathrm{T} 1}=6.911 \mathrm{~mA} \\
\mathrm{I}_{\mathrm{T} 2}=308.9 \mathrm{uA} \\
\mathrm{I}_{\mathrm{T} 3}=30.89 \mathrm{uA}\end{array}$ & $\begin{array}{c}\mathrm{I}_{1}=6.912 \mathrm{~mA} \\
\mathrm{I}_{2}=307.9 \mathrm{uA}\end{array}$ & $\begin{array}{c}\mathrm{I}_{1}=6.947 \mathrm{~mA} \\
\mathrm{I}_{2}=307.1 \mathrm{uA}\end{array}$ & 0.50 \\
\hline $\begin{array}{c}\text { Frequency Circuit } \\
\mathrm{F}_{\mathrm{T}}=50 \mathrm{~Hz} ; \mathrm{V}_{\mathrm{T}}=5.6 \mathrm{~V}\end{array}$ & $50.69 \mathrm{uA}$ & $\mathrm{I}_{3}=30.59 \mathrm{uA}$ & 0.32 \\
\cline { 2 - 4 } & $5.6 \mathrm{~V}$ & $49.99 \mathrm{~Hz}$ & 0.02 \\
\hline
\end{tabular}

\section{B. System time response}

The goal of this test is to estimate the system time response when users are acceding to the lab in a concurrent mode. We have developed a software application in Java that simulates until 60 users' requests at the same time.

Each one of these requests includes a CUT configuration and instruments setup. Depending on the number of the connections that the switching matrix has to perform, the system time response is different so we have use three different CUT configuration: a simple circuit that consist on only connection, a medium circuit that implements a circuit with 2 components and a complex circuit that uses 3 components. The results of these experiments are included at Table II. The obtained time responses have been compared with the times response of the VISIR lab in order to compare both control models. All the values are given in milliseconds.

If the circuit complexity or the number of simultaneous requests is increased, the system requires more time to response to the user's requests. Also it is noticed how the VISIR system is considerably faster than the proposed system because if a complex circuit must be implemented, its time response is less than the time required by the proposed model to build a simple circuit. According to [9] if a user has to wait more than 7 second, he will lose his attention an interest in it, so the system time response may be considered valid because the user will not be more than 7 seconds waiting for his answer. Anyway this feature should be improved in following developments.

\section{CONCLUSION AND FUTURE WORK}

Control and measurement systems commonly used in remote labs must have some performance and reliability features closest as much as possible to those obtained in a manual laboratory.

We have presented a model to control and measure electronics circuits using real instruments through Internet using a remote lab. The model has been validated using a complete and operative prototype. The main advantages of the proposed model are that it can be easily update and its adaptability to new experiments and instruments. Its mod-
TABLE II.

SYSTEM TIME RESPONSE IN MILLISECONDS

\begin{tabular}{|c|c|c|c|c|c|c|}
\hline \multirow{2}{*}{ Users } & \multicolumn{2}{|c|}{$\begin{array}{c}\text { Easy } \\
\text { Circuit }\end{array}$} & \multicolumn{2}{c|}{$\begin{array}{c}\text { Medium } \\
\text { Circuit }\end{array}$} & \multicolumn{2}{c|}{$\begin{array}{c}\text { Complicated } \\
\text { Circuit }\end{array}$} \\
\cline { 2 - 7 } & VISIR & $\begin{array}{c}\text { Pro- } \\
\text { posed } \\
\text { Method }\end{array}$ & VISIR & $\begin{array}{c}\text { Pro- } \\
\text { posed } \\
\text { posed } \\
\text { Method }\end{array}$ & VISIR & Method \\
\hline 10 & 408,5 & 777,1 & 444,7 & 1129,4 & 631,7 & 1189,4 \\
\hline 30 & 1195 & 2019,6 & 1287,4 & 3235,6 & 1874,4 & 3554,3 \\
\hline 60 & 2347,9 & 4803,5 & 2662,2 & 6341 & 3679,9 & 6919,3 \\
\hline
\end{tabular}

ular design guarantees the possibility of adding new instruments and components to the CUT easily without software or hardware reconfiguration. In short, the software is transparent to the experiments of the lab. The main features of the proposed model are:

a) It is an scalable and open structure to add new instruments and components.

b) It uses only commercial instruments. No proprietary and complex solutions are developed

c) Using IVI and VISA technologies allow to make the control application independent from the hardware and the communications interface.

d) Reliable measurements can be carried out because the hardware in charge of building the circuits do not introduce errors in the obtained results.

Regarding to future work, in one hand the system needs to improve the time response in concurrent mode. On the other hand the configuration of the switch matrix is one of the existing possibilities, so new configurations can be studied

\section{REFERENCES}

[1] Gomes, L., Bogosyan, S. "Current Trends in Remote Laboratories", IEEE Transactions on Industrial Electronics. Vo. 56, Issue 12, pp. 4744-4756 December 2009 http://dx.doi.org/10.1109/ TIE.2009.2033293

[2] Feisel, L.D. et al., "Learning objectives for engineering education laboratories," presented at the Frontiers in Education (FIE) 32nd Annual Conference, 2002

[3] Garcia-Zubia, J., Orduna, P., Lopez-de-Ipina,D., Alves, G.R. "Addressing Software Impact in the Design of Remote Laboratories" IEEE Transactions on Industrial Electronics, Vo. 56 Issue 12, pp. 4757-4767, December 2009 http://dx.doi.org/10.1109/ TIE.2009.2026368

[4] Machotka, J. and Nedic, Z. "Students' telepresence in a remote laboratory: a case study - NetLab", Proceedings of the International Conference on Engineering Education and Research - Progress Through Partnership, Farana, R. et al (Ed.). Bouzov Castle, Czech Republic, pp. 1237-1242. 2004

[5] Sousa, N., Alves, G.R., Gericota, M.G. "An Integrated Reusable Remote Laboratory to Complement Electronics Teaching," IEEE Transactions on Learning Technologies, Vol. 3, pp. 265-271. July-Sept. 2010 http://dx.doi.org/10.1109/TLT.2009.51

[6] Bagnasco, A., Chirico, M., Scapolla, A.M. "A New and Open Model to Share Laboratories in the Internet", IEEE Transaction on Instrumentation and Measurement, Vol. 54, pp 1111-1117. ISSN 0018-9456, June 2005.

[7] Harward, V.J., del Alamo, J.A., Lerman, S.R., Bailey, P.H. et al. "The iLab Shared Architecture: A Web Services Infrastructure to Build Communities of Internet Accessible Laboratories", Proceedings of the IEEE. Vol. 96, Issue 6, pp.931, ISSN: 0018-9219. June 2008 
[8] Gustavsson, I., Nilsson, K., Zackrisson, J., Garcia-Zubia, J., Hernández-Jayo, U., Nafalski, A., Nedic, Z., Gol, O., Machotka, J., Pettersson, M.I., Lago, T.,Hkansson, L. "On Objectives of Instructional Laboratories, Individual Assessment, and Use of Collaborative Remote Laboratories" IEEE Transactions on Learning Technologies, Vol 2, Issue 4, pp. 263-274. 2009 http://dx.doi.org/10.1109/TLT.2009.42

\section{AUTHORS}

U. Hernández-Jayo and J. García-Zubía are with the Faculty of Engineering, University of Deusto, Bilbao, Spain.

This article is an extended and modified version of a paper presented at the International Conference on Remote Engineering \& Virtual Instrumentation (REV2012), held at University of Deusto, Bilbao, Spain, July 4-6, 2012. Received 17 July 2012. Published as resubmitted by the authors 28 November 2012. 